\title{
Women, science and development: The leading role of OWSD
}

\author{
Alberto Quadrio-Curzio ${ }^{1,2} \cdot$ Tonya Blowers $^{3} \cdot$ Jennifer Thomson ${ }^{3,4}$ \\ Published online: 8 February 2020 \\ (c) Springer Nature Switzerland AG 2020
}

\section{One evaluation from three experiences}

This Editorial has three authors who share the same evaluation from different points of view on the issue of Women in Science for human development. ${ }^{1}$ The three experiences converge in 2020 in the same event which is the OWSD (Organization for Women in Science for the Developing World) 6th General Assembly and International Conference on Women in Science and Technology in the Developing World to be held at ICTP, Trieste (19-23 October, 2020). The focus of this Editorial is OWSD, which in 2018 had its 25th Anniversary since the official launch in Trieste (Italy) in 1993 and whose statutory mission is the following:

To increase the participation of women in developing countries in scientific and technological research, teaching and leadership; to promote the recognition of the scientific and technological achievements of women scientists and technologists in developing countries; to promote collaboration and communication among women scientists and technologists in developing countries and with the international scientific community as a whole; to increase access of women in developing countries to the socio-economic benefits of science and technology; to promote the participation of women scientists and technologists in the sustainable and economic development of their country; and to increase understanding of the role of science and technology in supporting women's development activities.

Attention to the promotion of women scientists in the South is particularly in line with the United Nation's Sustainable Development Goals (SDGs).

\footnotetext{
1 Alberto Quadrio-Curzio wrote Paragraphs 1, 2 and 5. Tonya Blowers, OWSD Coordinator, wrote Paragraphs 1, 3 and 5. Jennifer Thomson, OWSD President, wrote Paragraphs 1, 4 and 5.

Alberto Quadrio-Curzio

alberto.quadriocurzio@unicatt.it

1 Università Cattolica, Milan, Italy

2 Accademia Nazionale dei Lincei, Rome, Italy

3 Organization for Women in Science for the Developing World (OWSD), Trieste, Italy

4 University of Cape Town, Cape Town, South Africa
} 
For this reason, in Italy two important international prizes were awarded in 2017 and 2019 to women scientists by two Italian Institutions which have a "natural complementarity" between them and with OSWD without any institutional links. One is the Balzan International Prize Foundation; and the other is one of the annual prizes from the Accademia Nazionale dei Lincei. Over half a century, the ItalianSwiss Balzan Foundation has reached the milestone of one hundred prize winners, awarding annual prizes in humanities and the natural sciences. The Accademia Nazionale dei Lincei, the oldest scientific academy in the world, founded in 1603, is now considered the top cultural Institutions of the Italian Republic.

OWSD, whose headquarters are based in Trieste, Italy, is actively engaged and deeply committed to empowering and training young and early career women scientists, especially those from least developed countries (LDCs). OWSD's activities constitute a fresh approach to the broader field of international cooperation and aid for development. OWSD's work is an essential contribution since, by choosing to invest in human capital (Ph.D. and Early Career fellowships and awards), OWSD can counteract the typical problems that reduce the effectiveness of actions brought by international development agencies. Instead of funding large infrastructural and institutional programmes, OWSD directly invests in individuals. This approach has the potential to readdress current development cooperation practices, from institutional-oriented processes to individual-oriented processes. Although it should be noted that there is an intended feedback loop, so that once individuals are trained to 'capacity' they can influence and guide practices in their home institutions. OWSD itself, as an indirect funder, can also influence institutions to adopt more gender transformative practices (such as having sexual harassment policies in place or having a Gender Office on campus). It is interesting to note that OWSD funding comes directly from only two countries, Canada and Sweden. Both countries support OWSD activities through their two institutional national funds for scientific cooperation: SIDA-the Swedish International Development Cooperation Agency (Sweden) and IDRC - the International Development Research Centre (Canada).

Women's inclusion and empowerment in science means bringing in a different and complementary point of view that has the potential to produce a high positive impact on the final output for human progress.

\section{Two Italian International Prizes to women scientists from the South}

Let us consider two International Prizes delivered by Italian scientific institutions that have a "natural complementarity" although no institutional link: one is the Balzan International Prize (sponsored by the Italian-Swiss Foundation); the other is an annual prize awarded by the Italian Accademia Nazionale dei Lincei.

The 2017 Balzan Prize was awarded in "Gender Studies" to Bina Agarwal with the following motivation: "For challenging established premises in economics and the social sciences by using an innovative gender perspective; for enhancing the visibility and empowerment of rural women in the Global South; for opening new intellectual and political pathways in key areas of gender and development". 
The clearest and most synthetic explanation of Agarwal's work was made herself in a speech she gave on 11th November 2017 when she received the Balzan Prize in the Swiss Parliament. Agarwal said:

When I began my research career some forty years ago, rather little attention was paid to economic inequality in general, and gender inequality in particular. Today, overall economic inequality has moved to centre stage, but gender inequality remains largely on the margins of most research and policy. Yet it is perhaps the deepest form of persisting inequality we face today, especially as it intersects with the inequalities of class, caste, and race. And it adversely affects not just a country's economy but also its social and political fabric. Indeed, gender inequality is embedded in all our major institutions - the family, the market, the community, and the state. Many aspects of it remain invisible, however, hidden within gendered social norms that are often incorrectly seen as nature-given, or justified in the name of tradition.

The 2018/1 Issue of Economia Politica, published an Editorial by Bina Agarwal on 'The challenge of gender inequality' which was introduced by my Correspondence. In that Correspondence I described what I see as Agarwal's fundamental contribution:

I believe her contributions offer to economists a new paradigm on the economics of human and sustainable development, and institutional analysis. Let me stress some points that I find especially striking. Bina Agarwal has done sustained pioneering research not just in one field of economics but also in several major fields, from a political economy and gender perspective. Her writings cover agriculture and food security; inequality in property and land; poverty and sustainable livelihoods; collective action; and environmental governance. Few academics have written with such authority on such a wide range of major fields and contributed with originality in each.

In 2019, the Accademia Nazionale dei Lincei awarded its Tartufari Prize, dedicated to those who have demonstrated the "Protection of human rights" to Jennifer Thomson, President of the Organization for Women in Science for the Developing World (OWSD) with the following motivation:

Jennifer Thomson [...] has contributed to the development of human rights by promoting the contribution that women scientists give in the fields of health and education, agriculture and food, with the use of appropriate policies and techniques in the poorest and most vulnerable areas of the world, she herself has made important contributions to the production of genetically modified maize resistant to viruses and droughts especially in Africa. In this way, women are affirming how the development of science can contribute to making human solidarity concrete and in line with the UN Agenda 2030.

Jennifer Thomson is currently Emeritus Professor in the Department of Molecular and Cell Biology at the University of Cape Town (UCT). Her research field is 
the development of genetically modified maize resistant to the African endemic maize streak virus and tolerant to drought and she has published three books on Genetically Modified Organisms: Genes for Africa; Seeds for the Future; and Food for Africa. She is a member of the board of the African Agricultural Technology Foundation (AATF), based in Nairobi and vice-chair of ISAAA (International Service for the Acquisition of AgriBiotech Applications). Thomson also serves on the National Advisory Council on Innovation of the South African Minister of Science and Technology.

The Prize's motivation considers three aspects which converge in the award to Jennifer Thomson: promoting science and the education of women in LDCs within OWSD; applying science in African agriculture in order to increase food production in arid lands; promoting - through OWSD — the contribution of women in science to the development of human solidarity and the fulfilment of Agenda 2030.

I feel that both Prizes demonstrate the growing attention expressed by Italian scientific institutions towards women in science for the promotion of human development and women's rights, especially in developing countries and, more generally, for gender-equal opportunities.

Many examples can be presented but among them let us consider an important guest lecture series presented by women scientists in the academic year 2017-2018 when I was President of the Accademia dei Lincei.

This initiative of six complementary lectures was titled "Leading women belonging to science and politics" and was held at the Accademia in the first semester of 2018. The distinguished women in the field of sciences and politics were: Bina Agarwal (economist, Lincei fellow) who spoke on the topic "Equality and food security"; Fabiola Gianotti (physicist, CERN Director General, Lincei fellow) on the topic "Cern, a world-class laboratory for research and much more"; Elena Cattaneo (Senator of the Italian Republic and biologist, Lincei fellow) on the topic "Science and politics: from dialogue to feasible integration"; Emmanuelle Charpentier (genetist) on the topic "Crispr-Cas 9: a game changer in genetic engineering"; Berit Reiss-Anderssen (Lawyer, President of the Committee for the Nobel Peace Prize) on the topic "The Nobel Peace Prize"; and Marcella Frangipane (archeologist, Lincei fellow) on the topic "Archeology as a global science: interdisciplinarity and the reconstruction of past societies". Concluding, it is important to note here that in 2019 Fabiola Gianotti was the first ever woman DG of CERN and the first DG to be renewed for a second term of office.

\section{Women, science and development: results from the field}

It is well documented that advanced research in science, technology, engineering and mathematics (STEM) can lead to improvements and solutions to many of the challenges that individuals and communities face in the developing world, including climate change and natural disasters, disease, sanitation, housing and food security. Indeed, research in STEM has a fundamental role to play in each of the seventeen Sustainable Development Goals (SDGs) set by the United Nations General 
Assembly in 2015 , to be achieved by the year 2030. While it is much easier to see the direct impact on economies of applied research in fields such as technology, engineering and medicine, the 'pure' or basic sciences (such as some strands of mathematics, chemistry and biology) can also play a pivotal role in building and sustaining knowledge economies, as well as continually updating the theoretical basis on which much applied research will later be founded. A wide-and, importantly, unpredictable - variety of theoretical scientific work can contribute to our understanding and our ability to solve problems even years after the research has been developed.

In order to approach the greatest challenges of the 2030 Agenda for Sustainable Development, societies around the world must access and harness all the talent and experience available to tackle such complex and wide-ranging challenges. The concerns and perceptions of the greatest number of all possible actors and recipients must be considered in order that the most relevant issues and effective solutions are found. Women are considerably underrepresented as researchers in STEM subjects around the globe-according to UNESCO Institute of Statistics (UIS) data, in 2019 the global average percentage of women researchers was still below $30 \%$. Yet women typically have first hand specialist knowledge of the day-to-day challenges diverse individuals face within communities and can be key informers in the design and development of their solutions. Moreover, since women are most often the providers of informal community support, if they are not fully informedand if solutions are developed without their consultation, it may be the case that products, services and solutions are not relevant or appropriate. Technological advances may mean improved machines on large farms, for example, potentially increasing food production, but since the key points of food insecurity in the world are on small-scale farms managed by women throughout the Global South, such capital investments will have little impact in the areas where food production is most critical-and where women's knowledgeable implementation of appropriate innovative technologies could make the most difference.

It is clear that a significant increase in the number of women entering and remaining in STEM careers would go a long way to improving the relevance in scientific research design, outcomes and implementation-and as a result, the impact on the economy. Furthermore, sustainable development requires more science and more scientists, meaning that a higher number of girls and women entering and remaining in STEM careers is not just desirable but essential.

The programmes OWSD has developed over 30 years are designed to address the 'numbers problem', by increasing the opportunities for women from developing countries to do advanced STEM research at international level as well as increasing their visibility and recognition. OWSD programmes can be seen to fall into four categories (which I will describe below)-and these categories are also, I believe, the fundamental categories that any organisation working in the field of science and development can use to map out an effective strategy to increase participation in science:
(1) Community
(2) Mobility 
(3) Capacity
(4) Visibility

Recipients of OWSD-funded programmes are outstanding individuals, women scientists from developing countries who show enormous potential to achieve ground breaking research of relevance to the social and economic development of their countries, as well as to lead, influence and inspire the young women they meet and work with to become scientists or to continue on the challenging career ladder ahead.

\section{(1) Community}

The bright star in the OWSD constellation of opportunities is community. In early 2020 OWSD had over 9,000 members (in 133 countries) and 28 active national chapters. OWSD members are women from developing countries with at least a Masters in the natural or social sciences. ${ }^{2}$ Members may organize national chapters in order to promote women's participation in science and technology and in scientific leadership at the national and regional levels. At least 20 full members are necessary in order to form a National Chapter. Once Chapters are established, members carry out strategic activities according to priorities they identify within their own countries, including outreach to schools and the public, organization of conferences, workshops, and training opportunities for women scientists, contributions to policy development, and data collection on the status of women in science in their countries.

Despite the fact that-at least until 2019-OWSD did not provide any direct funds to the national chapters, the commitment and enthusiasm of the membership has always been impressive. Struggling women scientists around the globe are eager to find solutions to the specific challenges they face and simply the fact of being directly linked to an international organization (OWSD is a UNESCO programme, and is hosted by TWAS and ICTP), makes a huge difference to the legitimacy and importance of their local activities.

Added to this, there is the proven importance of networking at local, national, regional and international level for women scientists. At national chapter meetings, women scientists often meet each other for the first time, they share their research findings, and their challenges.

Women, because of gender expectations and norms, make up the vast majority of those responsible for children's education and nutrition. Women all over the globe tend to dedicate more time and energy caring for those who cannot be fully independent: the sick, the elderly, people with disabilities and special needs.

\footnotetext{
2 Younger, 'Affiliate' members with Bachelor's degrees are also encouraged to join the network, as are 'Friends' of OWSD who are not eligible for membership but can be men or women from developing or developed countries who wish to support the Organization.
} 
While these social contributions are essential to the wellbeing of the community they are often not remunerated or recognised. Indeed, women tend to spend around 2.5 times more time on unpaid care and domestic work than men.

The national chapter model is highly effective for encouraging young women to participate in science. Most importantly, the specific needs of women scientists are discovered and discussed at the local level (and OWSD receives their feedback and input) while being affiliated to an international organization with common objectives which can link women with other scientists in their countries, in their region and between regions. This means that OWSD has first-hand knowledge of the widely varying challenges that women face in diverse cultures. So, while OWSD is an organization for 'women from developing countries' it still manages to differentiate the nuances of each woman's difficulties and successes. This knowledge, provided by standardized reports from our national chapter executive committee members, and in turn from their regional representatives on the OWSD executive board, then feeds into the design and implementation of OWSD programmes and strategic planning.

\section{(2) Mobility}

In order to meet, learn from and exchange knowledge and experience with the most respected and knowledgeable researchers in their specialist field, researchers need to be mobile-but childcare responsibilities, and, in some cultures, partners or parents who refuse to give their permission before a woman can leave the country, mean the playing field is rarely even for men and women.

By definition, the countries OWSD supports are poorly resourced. They include all Least Developed Countries (LDCs) and some additional ones, which OWSD (with TWAS-Third World Academy of Sciences) has identified as 'scientifically and technologically lagging' (STLCs). Women (and men) living in such countries who want to follow higher education face many challenges. Often there are few-and poor-universities. Laboratories are non-existent or very poorly equipped. There is little money for consumables. Teachers and lecturers are often not educated to Ph.D. level. This means that if a woman (or man) in an STLC wants to do scientific research at an international level she or he must leave the country. Mobility is key.

Women face specific challenges to being mobile husbands and fathers may be gatekeepers; and childcare commitments may make it hard for them to move. Finding the funds, being given the time and the permission to attend a conference in order to make regional and international connections may be only a dream.

OWSD has tackled this challenge of mobility through a well-established 'South to South' Ph.D. fellowship programme which has evolved over 25 years (initially based on the TWAS model and adapted to suit the specific needs of women scholars) and thanks to the funding long-term commitment and vision of SIDA. The programme has evolved over the years to respond to the needs women scientists have and with great success in early 2020 there were over 270 graduates (and counting) from the programme.

This programme offers both full and part-time scholarships for women from STLCs to study in another developing country and encourages regional 
collaborations and movement (which may well continue beyond the Ph.D. period). Since the host institute is also in a developing country, there is great potential for double capacity building, since the host institute is receiving fully-funded international scholars who have been selected through a rigorous review process, and who bring their own expertise and interests (and sometimes literally their highly-valued consumables and samples) to a research institute that, despite all the challenges, has managed to carve out a reputation that is good enough to attract scholars from outside the country. Regional movement within a continent, rather than "internationally" may be preferable for many young women who may never have left their home town before, let alone their country. This will often be their first experience living independently and without the day-to-day support of the extended family and community. There is evidence that south to south (as opposed to south to north) movement can combat brain drain, without the attractions of booming economies and the (apparently easy) wealth and employment opportunities. Often, South to South movement encourages a richer collaboration and exchange since the research interests are often more relevant (for example, rice culture in agricultural science projects moving from Bangladesh and Myanmar to Malaysia) or because the climatic conditions are similar (diseases caused by mosquitoes such as malaria or typhoid fever may share similar patterns in Rwanda and South Africa, for example). In addition, South to South movement is likely to reduce the impact of so-called 'culture shock'. Moving within regions may be far more sustainable and endurable than moving between continents. Often the climate is similar-and cultural traditions, though different may still be comprehensible.

\section{(3) Capacity}

The greatest challenge for development organizations, NGOs and agencies is how to make the biggest impact; how to affect the quality of life of the greatest number of people with the least funds. And also, how to encourage sustainable development so that a country can continue to support its own research infrastructure once the initial funding has dried up? A related question is whether to invest in individuals or institutions? And another hugely problematic question is how to counteract brain drain, which is often seen as a failed investment in human capital. But this is also an ethical question. Do we have the right to proscribe that highly talented researchers from the poorest countries must stay home, where it is likely they have fewer resources and opportunity to carry out cutting edge research? Are we, in effect, dis-enabling them from being successful researchers? And indeed, is this actually in the best interests of their country, when international reputation and expertise (let alone remuneration) may well in the long term feed back to their country of birth-the potential contribution of the diaspora. Are we (once again) requiring women scientists to sacrifice their careers-in this case, for the sake of the altruistic development of their country?

The OWSD Early Career Fellowships seeks to address some of these questions. The uniquely flexible grant, up to USD50,000 to each Fellow funded by the Canadian International Development Research Centre (IDRC), allows women to select the resources they need that will help them to stay at home in under-resourced 
countries-perhaps a lab space, lab equipment, consumables. But perhaps also funds to invite visiting scholars, to create a seminar series, to attend conferences. To buy software for data visualisation or to develop a patent. To publish in open access journals. To hire a technician or an MSc student. To pay for childcare support or assistance with an elderly parent. To negotiate a reduction in teaching load.

For example, a current Early Career Fellow from Nepal, is employed as a Research Scientist at the Center for Water and Atmospheric Research at the Kathmandu Institute of Applied Sciences. The project for which she was awarded the OWSD grant is to "Build a low cost mobile weather station for drought study in Nepal" and with part of her funding from OWSD she has been able to hire and pay for a research assistant and program manager. An OWSD Fellow from Sri Lanka, employed as a Research Professor in the Ecosphere Resilience Research Center, at the University of Sri Jayewardenepura is working on "Carbonized biowaste based integrated treatment train for the leachate from open dumpsites" and with OWSD support she has been able to hire and pay for a research assistant. A Research Associate from Senegal, employed in the Virology and Virus Unit of the Institut Pasteur in Dakar was awarded OWSD funds for her project on the "Identification of mosquito saliva proteins involved in the enhancement of Rift Valley Fever virus infectivity in vertebrate hosts" and with OWSD support she has been able to hire and pay for a laboratory technician. The OWSD grant also includes training in procurement procedures so that Fellows can purchase equipment and, importantly, cover the costs of training technicians and maintenance staff to ensure the equipment can be used. Each fellowship lasts just 2 years and includes two training workshops (the first in Trieste and the second in one of the four OWSD regions). As well as team-building, leadership and negotiating skills, fellows learn how to link their research with industry and the private sector, including how to develop prototypes and apply for patents, thereby sustaining the research beyond the OWSD support. The aim is to provide Fellows with enough resources that they can build up a research team and centre that will be recognised internationally and attract high calibre visitors, so that, rather than having to travel abroad in search of excellence and inspiration, international collaborators will elect to come to them.

\section{(4) Visibility}

Increasing the visibility of women scientists from developing countries has many benefits both for the individual scientist, for her specific scientific and geographic community, and for science (and thereby the economy, as argued earlier). Young women from the poorest countries-and countries with the lowest investment in science-are inspired to emulate the role models they see succeeding in similar circumstances: "if she can do it, then so can I". Launched in 2013, the OWSD-Elsevier Foundation Awards for Early Career Women Scientists reward and encourage women at the early stages of their scientific careers, who have overcome great challenges to achieve research excellence. Awardees must have made a demonstrable impact on the research environment, both at a regional and international level, and must have received their Ph.D. in the last 10 years. 
Five awards are made each year (one from each of the four OWSD regions plus one additional outstanding candidate) on a 3-year rotation of disciplinary categories, including: agriculture, biology and medicine; engineering, innovation and technology; and chemistry, mathematics and physics. The award itself is modest: each winner receives a cash prize of USD 5000. However, each winner is also sponsored to attend the annual meeting of the American Association for the Advancement of Science (AAAS), held every year in February in a selected American city. The winners receive their awards at a special networking ceremony, and have the possibility to attend workshops and sessions at the AAAS meeting, visit local laboratories and institutions, and attend a celebratory dinner organized by the Elsevier Foundation. The AAAS meeting is an important opportunity to establish contacts and collaboration networks with colleagues from all over the world. Often, the award is the gateway to other awards and recognition ('prizes attract prizes') — and in two cases, as a result of the OWSD-EF award, the presidents of the awardees' countries have invited them for a visit, recognising - and celebrating - their international reputation. In general, the award has a knock-on effect: "Because of this Award and the international recognition, I am more confident, accountable and motivated to continue my research activities in order to achieve my goals. It will inspire many younger ladies in this region to achieve more in the advancement of sciences." Dr. Tista Prasai Joshi (Nepal) 2019 awardee.

While there are obvious benefits for the international collaborations of women scientists from developing countries to be showcased in the United States of America, and other developed countries, there are important downsides. Awardees may not be granted visas to attend the awards ceremony in the USA (for example awardees from Sudan and Yemen). In addition, while the ceremony may confer important benefits to the career opportunities and recognition of the individual awardee, the impact on her home country and region is reduced. It would be important-and special-if some awards could also be conferred in the home countries and regions of the awardees. For this reason, OWSD is hoping to develop prize ceremonies for 'best undergraduate woman in science' at university graduation ceremonies in OWSD eligible countries. This would also provide OWSD with the opportunity to present to an ideal 'target' audience, the benefits to female graduates (and to their communities) if they continue on to do a Ph.D. in science.

\section{The 25th anniversary in 2018}

The year 2018 marked the 25th Anniversary of OWSD, and more than 2,500 women scientists attended events organised by the OWSD membership around the world, to celebrate OWSD successes and to promote women's participation in science and technology and in scientific leadership at the national and regional levels. Events included a workshop on science communication in Kigali; regional conferences in Accra, Dacca, Harare, Nairobi and New Delhi; and ten 
days of celebrations in Khartoum (including a fun run; science for development competition; and promotional visits by fellows to universities around Sudan). These events were often combined with OWSD national chapter launches: in Mauritius (February), Rwanda (March), Sri Lanka (March), Indonesia (July), Kenya (September), Ghana and Myanmar (November) and Zimbabwe (December).

Sida provided special funding for these events, to cover venue and catering costs as well as sponsoring OWSD Ph.D. fellows to attend. Often, the main expenses were covered by local sponsors. In this way, the OWSD network was able to develop event management and fundraising skills among its members. Visibility for OWSD work in the regions was much enhanced and important dignitaries attended launch events including, for example, the (then) President of Mauritius and OWSD member Dr Ameenah Gurib-Fakim.

\section{Conclusion}

In order to showcase the scientific results from these programmes, as well as to enable members to meet and network, to provide tailored training workshops, and to elect the new executive board members, every 4 years OWSD hosts a General Assembly and International conference. The last Assembly, hosted and mostly funded by the Kuwait Institute for Scientific Research, attracted 500 women participants from developing countries. In 2020, for the first time in OWSD's history, the General Assembly and conference will not be held in a developing country-but will be held instead in Trieste, in Italy.

This is an important strategic decision, which combines the fact that OWSD has its headquarters in Trieste with a serendipitous historical event to be hosted by Trieste: thereby reflecting both OWSD's history and a pivotal moment for the city itself. In 2020, Trieste has been selected as the European City of Science and will host the EuroScience Open Forum (ESOF), including a Science in the City festival, in June and July.

The OWSD Secretariat is based on the campus of the International Centre for Theoretical Physics (ICTP) in Trieste, which was founded by Nobel Prize winner from Pakistan, Abdus Salam with the support of the Italian Republic. ICTP was conceived as a resource centre and breathing space for established scientists from the developing world to use the library and academic resources, collaborate with internationally recognised physicists on campus and take a break from intensive teaching commitments. Today, ICTP's remit has expanded to include other disciplines (Maths and Quantitative Life Sciences) as well as to host over 60 conferences per year and accommodate up to 6000 visitors from the developing world. Salam also established on the same campus.

The Third World Academy of Sciences (TWAS), also supported by the Italian Republic, as a means to provide an arena and network for outstanding scientists in all disciplines from developing countries, who still very often do not have an opportunity to be selected as members of other science academies. It was during a TWAS conference on 'The Role of Women in the Development of 
Science and Technology in the Third World' organised by Abdus Salam in 1988, that the idea and need for an organization that would focus entirely on women scientists was born-and 5 years later OWSD was established. TWAS, OWSD and ICTP belong to the 'Trieste Science System' which includes other notable institutes of international repute, often with a specialised interest and expertise in developing world scientists and science, including the International Centre for Genetic Engineering (ICGEB), Elettra-Sincrotone, the University of Trieste and the International School for Advanced Studies (SISSA) which has Italy's largest number of international Ph.D. students in Neuroscience, Biology, Maths and Physics.

Being celebrated and visible in Europe (and Italy) for the first time, it is hoped that the OWSD General Assembly will attract the attention of European (and Italian) funders as well as providing face-to-face international scientific collaboration opportunities for our visiting members.

The conference will have four main themes: (1) women, science and development; (2) gender, basic sciences and development; (3) sex and gender issues in science and (4) women, artificial intelligence and the developing world.

With this Editorial Economia Politica, Journal of analytical and institutional economics wanted to give its contribution to the knowledge of OWSD and to the success of the OWSD 2020 General Assembly.

Publisher's Note Springer Nature remains neutral with regard to jurisdictional claims in published maps and institutional affiliations. 